\title{
miR-218 inhibits the invasion and migration of colon cancer cells by targeting the PI3K/Akt/mTOR signaling pathway
}

\author{
XIANGLIANG ZHANG ${ }^{1 *}$, HUIJUAN SHI $^{2 *}$, HONGSHENG TANG $^{1}$, \\ ZHIYUAN FANG ${ }^{1}$, JIPING WANG ${ }^{3-5}$ and SHUZHONG CUI ${ }^{1}$
}

\begin{abstract}
${ }^{1}$ Department of Abdominal Surgery (Section 2), The Affiliated Cancer Hospital of Guangzhou Medical University, Guangzhou, Guangdong 510095; ${ }^{2}$ Department of Pathology, The First Affiliated Hospital of Sun Yat-Sen University, Guangzhou, Guangdong 510080, P.R. China; ${ }^{3}$ Department of Surgery, Brigham and Women's Hospital affiliated to Harvard Medical School, Boston, MA 02115; Departments of ${ }^{4}$ Surgery and ${ }^{5}$ Pathology, Massachusetts General Hospital affiliated to Harvard Medical School, Boston, MA 02114, USA
\end{abstract}

Received December 12, 2014; Accepted February 26, 2015

DOI: $10.3892 / \mathrm{ijmm} .2015 .2126$

\begin{abstract}
Colon cancer is one of the most common and lethal malignancies worldwide. Despite major advances in the treatment of colon cancer, the prognosis remains very poor. Thus, novel and effective therapies for colon cancer are urgently needed. In the present study, the expression status of miR-218 and the role of the phosphoinositide 3-kinase (PI3K)/protein kinase B (Akt)/mammalian target of rapamycin (mTOR) pathway were investigated in colon cancer samples. Firstly, we observed that miR-218 expression was significantly reduced, while PI3K/Akt/mTOR pathway activity was enhanced. The overexpression of miR-218 suppressed the proliferation, migration and invasion of LoVo colon cancer cells, whereas the inhibition of miR-218 promoted these processes. Furthermore, the PI3K/Akt/mTOR signaling pathway was identified as a direct target of miR-218. The upregulation of miR-218 inhibited the activation of the PI3K/Akt/mTOR signaling pathway, as well as the expression of matrix metalloproteinase (MMP)9. The downregulation of miR-218 activated the PI3K/Akt/mTOR signaling pathway and promoted MMP9 expression. Taken together, our results demonstrate that miR-218 suppresses the proliferation, migration and invasion of LoVo colon cancer cells by targeting the PI3K/Akt/mTOR signaling pathway and MMP9. Our data indicate that miR-218 is a potential target in the treatment of colon cancer.
\end{abstract}

Correspondence to: Professor Shuzhong Cui, Department of Abdominal Surgery (Section 2), The Affiliated Cancer Hospital of Guangzhou Medical University, 78 Hengzhigang Road, Guangzhou, Guangdong 510095, P.R. China

E-mail: 513340728@qq.com

*Contributed equally

Key words: miR-218, PI3K/Akt/mTOR, invasion and migration, LoVo colon cancer cells

\section{Introduction}

Colon cancer is the second most common type of cancer and the fourth leading cause of cancer-related mortality worldwide $(1,2)$. Indeed, the lifetime risk of developing colon cancer in the United States is approximately $20 \%$ (2), and in China the development of colon cancer is increasing each year (3). Despite major advances in the treatment of colon cancer, its prognosis remains very poor $(4,5)$. Frequent intraperitoneal metastases and post-surgical recurrence are characteristics of colon cancer and the major factors leading to poor prognosis $(6,7)$. Therefore, exploring the molecular mechanisms underlying the pathogenesis of colon cancer may provide valuable insight and aid in the development of novel and effective therapeutic approaches for colon cancer.

MicroRNAs (miRNAs or miRs) are a specific type of small non-coding RNA that modulate gene expression through the suppression of mRNA translation. The aberrant expression of miRNAs has been linked to tumor initiation, progression and prognosis (8-10). Of these cancer-associated miRNAs, miR-218 expression has been frequently observed to be decreased in human colon cancer $(11,12)$. Furthermore, it has been reported that the miR-218 expression level is associated with the TNM stage, and that miR-218 hypo-expression in sera and tissues is indicative of a poor prognosis in patients with colon cancer (13). However, the mechanisms of action of miR-218 in colon cancer progression remain elusive.

In addition to miRNAs the hyperactivation of the phosphoinositide 3-kinase (PI3K)/protein kinase B (Akt) signaling pathway is frequently observed in various types of cancer (14). The involvement of this pathway in the development of colon cancer and metastasis, including cell proliferation, apoptosis and migration, has been extensively investigated (15-18). Furthermore, the blockade of PI3K/Akt activity in colon cancer cells has shown promising anti-cancer effects (19-22). Recent studies have demonstrated that the downstream factor of the PI3K/Akt pathway, the mammalian target of rapamycin (mTOR), is a potential therapeutic target in various types of cancer, including non-small cell lung cancer (23), colorectal cancer $(24,25)$, 
renal carcinoma (26), non-Hodgkin's lymphoma (27) and leukemia $(28,29)$. In addition, the activation of the PI3K/Akt pathway has been shown to correlate with a poor prognosis in stage II colon cancer, and Akt phosphorylation is a prognostic factor for disease-free survival (30). These findings confirm that the PI3K/Akt pathway is essential for the development of colon cancer and is a promising target for the treatment of colon cancer.

It has been previously reported that the upregulation of miR-218 inhibits the proliferation of oral squamous carcinoma cells by targeting Akt and mTOR (31), and increases the sensitivity of gastrointestinal stromal tumor cells to imatinib through the PI3K/Akt pathway (32). In the present study, we also revealed that the PI3K/Akt signaling pathway may be a potential target of miR-218 using gene target prediction programs. Furthermore, the effect of miR-218 on the PI3K/Akt/mTOR signaling pathway was explored, and it was shown that miR-218 is a negative regulator of this pathway. Matrix metalloproteinase (MMP)9 was identified as a downstream factor of miR-218, and miR-218 inhibited MMP9 expression in colon cancer cells. Therefore, miR-218 was identified as a repressor of colon cancer development and progression by targeting the PI3K/Akt/mTOR signaling pathway and MMP9 expression. Consequently, miR-218 is a potential target in the treatment of colon cancer treatment.

\section{Materials and methods}

Reagents. The miRNA extraction kit was from Tiangen Biotech (Beijing) Co., Ltd. (Beijing, China). The TaqMan MicroRNA Assay kit, and TaqMan ${ }^{\circledR}$ Universal PCR Master Mix were purchased from Applied Biosystems (Foster City, CA, USA). TargetScan version 5.1 (http://www.targetscan.org/index.html) was used to find potential targets for miR-218.

Cell lines and colon tissue specimens. Human colon tissue specimens were obtained from patients with surgical resections performed at the Affiliated Cancer Hospital of Guangzhou Medical University (Guangdong, China). A total of 4 tumor tissue samples and adjacent normal tumor tissue samples were collected from 4 patients with colon cancer. The study was approved by the Ethics Committee of the Affiliated Cancer Hospital of Guangzhou Medical University, and legally effective informed consent was obtained from all patients.

Cell transfection. Human LoVo cancer cells (obtained from the Cell Bank of Sun Yat-Sen University) were seeded in 6-well plates at a final density of $8 \times 10^{4}$ cells/well and cultured overnight at $37^{\circ} \mathrm{C}$ in a humidified atmosphere of $95 \%$ air and $5 \% \mathrm{CO}_{2}$ prior to transfection. Subsequently, transfections were conducted for miR-218 mimic, non-specific control (NC) and miR-218 inhibitor using Lipofectamine 2000 (Invitrogen Life Technologies, Carlsbad, CA, USA) according to the manufacturer's instructions. The culture medium was changed from serum-free DMEM to DMEM containing 10\% fetal bovine serum (Gibco-BRL, Grand Island, NY, USA) $5 \mathrm{~h}$ after transfection. Following culture for a further $48 \mathrm{~h}$, total RNA and cellular protein lysates were collected and used for reverse transcription-quantitative PCR (RT-qPCR) and western blot analysis, respectively.

MTT assay. LoVo cells were seeded into 96-well plates $\left(8 \times 10^{4}\right.$ cells/well) and assessed by MTT assay. To determine viability, the cells were then treated with $5 \mathrm{mg} / \mathrm{ml}$ MTT for $4 \mathrm{~h}$ at $37^{\circ} \mathrm{C}$ and then the medium was carefully removed. The resulting formazan crystals were dissolved in $150 \mu$ l dimethyl sulfoxide (DMSO), and the absorbance at $570 \mathrm{~nm}$ was determined using a plate reader.

Protein extraction and western blot anlaysis. Total cellular proteins were extracted using lysis buffer containing $150 \mathrm{mM}$ $\mathrm{NaCl}, 10 \mathrm{mM}$ Tris at $\mathrm{pH} 7.2,0.1 \%$ SDS, $1.0 \%$ Triton $\mathrm{X}-100$, $1 \%$ deoxycholate and $5 \mathrm{mM}$ EDTA. Subsequently, protein levels were quantified using the Bio-Rad Protein Assay kit (Bio-Rad, Hercules, CA, USA). A total of $30 \mu \mathrm{g}$ protein was used for $10 \%$ sodium dodecyl sulphate polyacrylamide gel electrophoresis (SDS-PAGE) followed by transfer to PVDF membranes (Bio-Rad). The PVDF membranes were then incubated in 5\% milk dissolved in $1 \mathrm{X}$ TBST buffer at room temperature for $1 \mathrm{~h}$ to block the potential non-specific binding of primary antibodies. Subsequently, the primary antibodies, including mouse monoclonal anti-Akt (ab79360), anti-mTOR (ab134903) and anti-GAPDH (ab22556) antibodies (Santa Cruz Biotechnology, Inc., Santa Cruz, CA, USA), were added followed by incubation overnight at $4^{\circ} \mathrm{C}$. After washing with $1 \mathrm{X}$ TBST buffer, the corresponding secondary HRP-conjugated antibody (LS-C170893; Santa Cruz Biotechnology, Inc.) was added. After washing with $1 \mathrm{X}$ TBST buffer, the ECL chemiluminescent detection system (Pierce Biotechnology, Inc., Rockford, IL, USA) and X-ray films were used for protein detection. The blots were then scanned and the band density was quantified using the GeneGnome western blot imaging system (Syngene, Cambridge, UK) using GeneSnap software.

$R N A$ extraction and $R T-q P C R$. Total RNA was extracted from the cultured LoVo cells using the RNeasy Mini kit (Qiagen, Inc., Valencia, CA, USA). The isolated RNA was quantified by measuring its absorbance at $260 \mathrm{~nm}$. The expression level of matured miRNAs was analyzed by stem-loop reverse transcription followed by quantitative PCR (qPCR). All reagents for the stem-loop reverse transcription, including the TaqMan MicroRNA Assay kit and the TaqMan Universal PCR Master Mix were obtained from Applied Biosystems. miR-218 expression in the human colon tissue samples was normalized to the endogenous reference gene, GAPDH. For the detection of the mRNA expression of PI3K, Akt and mTOR, reverse transcription was performed using the PrimeScript ${ }^{\mathrm{TM}}$ RT reagent kit [Takara Biotechnology (Dalian) Co., Ltd., Liaoning, China]. qPCR was performed on a LightCycler 480 System (Roche, Basel, Switzerland) using SYBR Premix Ex Taq II [Takara Biotechnology (Dalian) Co., Ltd.]. GAPDH was used as the endogenous control. The $2^{-\Delta \Delta \mathrm{CT}}$ method was used to quantify the expression changes of target genes. Three independent experiments were performed.

Wound healing assay. Wound healing assay was conducted $48 \mathrm{~h}$ after cell transfection. An artificial homogeneous wound was created on the monolayer using a sterized $200 \mu \mathrm{l}$ micropipette tip when the cells reached approximately $90 \%$ confluency. Cell debris was removed by washing with DMEM twice. Wound closure via cell migration was observed $12 \mathrm{~h}$ later by capturing images using an inverted microscope with x40 objective (Olympus Corp., Tokyo, Japan). 
A

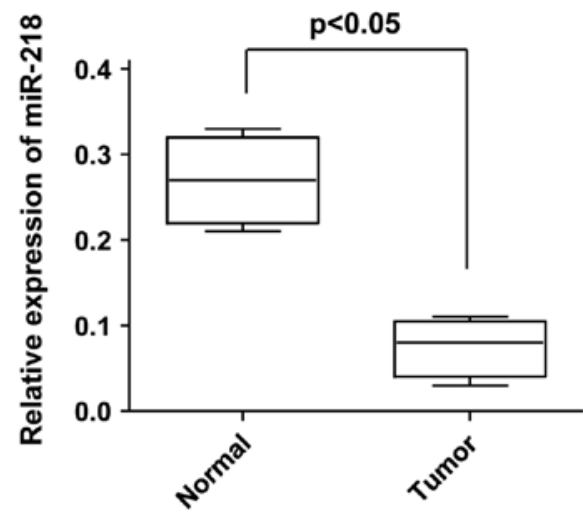

B

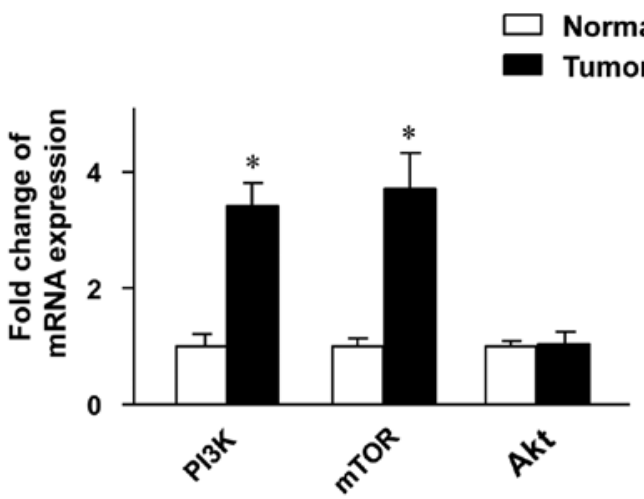

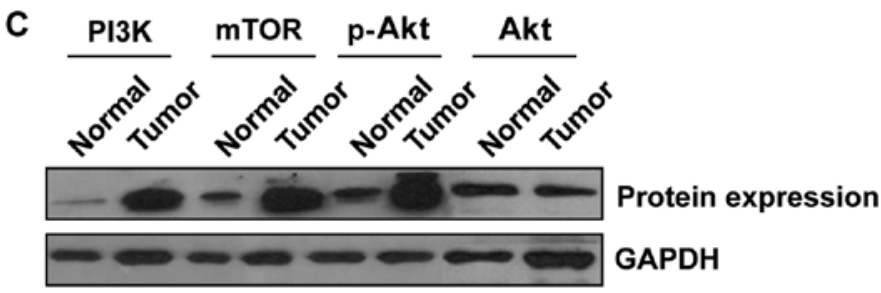

Figure 1. Aberrant miR-218 expression and phosphoinositide 3-kinase (PI3K)/protein kinase B (Akt)/mammalian target of rapamycin (mTOR) pathway activity in colon cancer tissue samples. (A) The miR-218 level was significantly lower in the colon cancer tissue as compared to the normal tissue samples. (B) The expression of PI3K and mTOR at the mRNA level was upregulated, while Akt mRNA expression only slightly altered in the tumor tissues. (C) The expression of PI3K and mTOR at the protein level was upregulated, while Akt protein expression was only slightly altered in the tumor tissues. The phosphorylation of Akt was enhanced in the tumor tissues. ${ }^{*} \mathrm{P}<0.05$.

Invasion and migration assays and immunofluorescence staining. Tumor invasion assay was performed as follows: friefly, an $8-\mu \mathrm{m}$ pore polycarbonate membrane filter was inserted into each Transwell chamber (Corning, Inc., Corning, NY, USA) and coated with $50 \mu \mathrm{l}$ of Matrigel (Sigma, St. Louis, MO, USA) with a final concentration of $4 \mathrm{mg} / \mathrm{ml}$. A total of $5 \times 10^{3}$ transiently transfected LoVo cells was then seeded into the upper chamber with $100 \mu \mathrm{l}$ of serum-free medium, and $1 \mathrm{ml}$ DMEM containing $20 \%$ FBS was added to the bottom chamber. The cells were incubated at $37^{\circ} \mathrm{C}$ for a further $48 \mathrm{~h}$. For immunofluorescence staining, the LoVo cells that had invaded into the lower surface of the filter were fixed with $4 \%$ paraformaldehyde and stained with crystal violet. Cells from 3 random visual fields per filter were captured using a microscope at x100 magnification and counted for quantification. Tumor cell motility assay was performed similarly to the Matrigel invasion assay, but without the Matrigel coating of the filter. For all assays, 3 independent experiments were performed.

Data analysis. Data are presented as the means \pm SD and analyzed using SPSS 13.0 software (SAS Institute, Inc., Cary, NC, USA). Significant differences/correlations between the different groups were calculated using the Student's t-test, $\chi^{2}$ test or Pearson's correlation. A value of $\mathrm{P}<0.05$ was considered to indicate a statistically significant difference.

\section{Results}

Aberrant changes in miR-218 expression and the PI3K/ Akt/mTOR pathway in colon cancer tissues. We first examined the miR-218 expression level in the colon cancer and adjacent normal tissue samples. It was shown that the expression level of miR-218 was significantly lower in the tumor tissues than in the adjacent normal tissues (Fig. 1A). The status of the $\mathrm{PI} 3 \mathrm{~K} / \mathrm{Akt} / \mathrm{mTOR}$ pathway in thetumor tissues was further analyzed, and the results revealed that the expression of PI3K and mTOR at both the mRNA and protein level was markedly increased in the tumor tissues compared to the adjacent normal tissues (Fig. 1B and C). Whereas the expression of Akt was only slightly altered at both the mRNA and protein level (Fig. 1B and C), the phosphorylation of Akt protein was significantly enhanced in the tumor tissues (Fig. 1C), which indicated that the PI3K/Akt/mTOR pathway was aberrantly activated in the colon cancer tissue samples.

Overexpression of miR-218 inhibits the proliferation, migration and invasion of LoVo colon cancer cells. As described above, miR-218 expression negatively correlated with the development of colon cancer. To investigate the causal role of miR-218 in the development of colon cancer, miR-218 mimics and inhibitors were transfected into the LoVo human colon cancer cells to examine the effect of miR-218 overexpression or inhibition on cell proliferation, migration and invasion. MTT assay revealed that cell proliferation was significantly inhibited by transfection with miR-218 mimics $(24.7 \pm 5.5 \%)$, while it was significantly promoted by transfection with miR-218 inhibitors (Fig. 2A).

In addition to its effect on cell proliferation, miR-218 was found to be critical for the migration and invasion abilities of the LoVo colon cancer cells. In the migration assay, the number of invading cells in the lower Transwell chamber was significantly decreased in the miR-218 mimic-transfected group (19.7+5.0\%), while this number was increased in miR-218 inhibitor- 

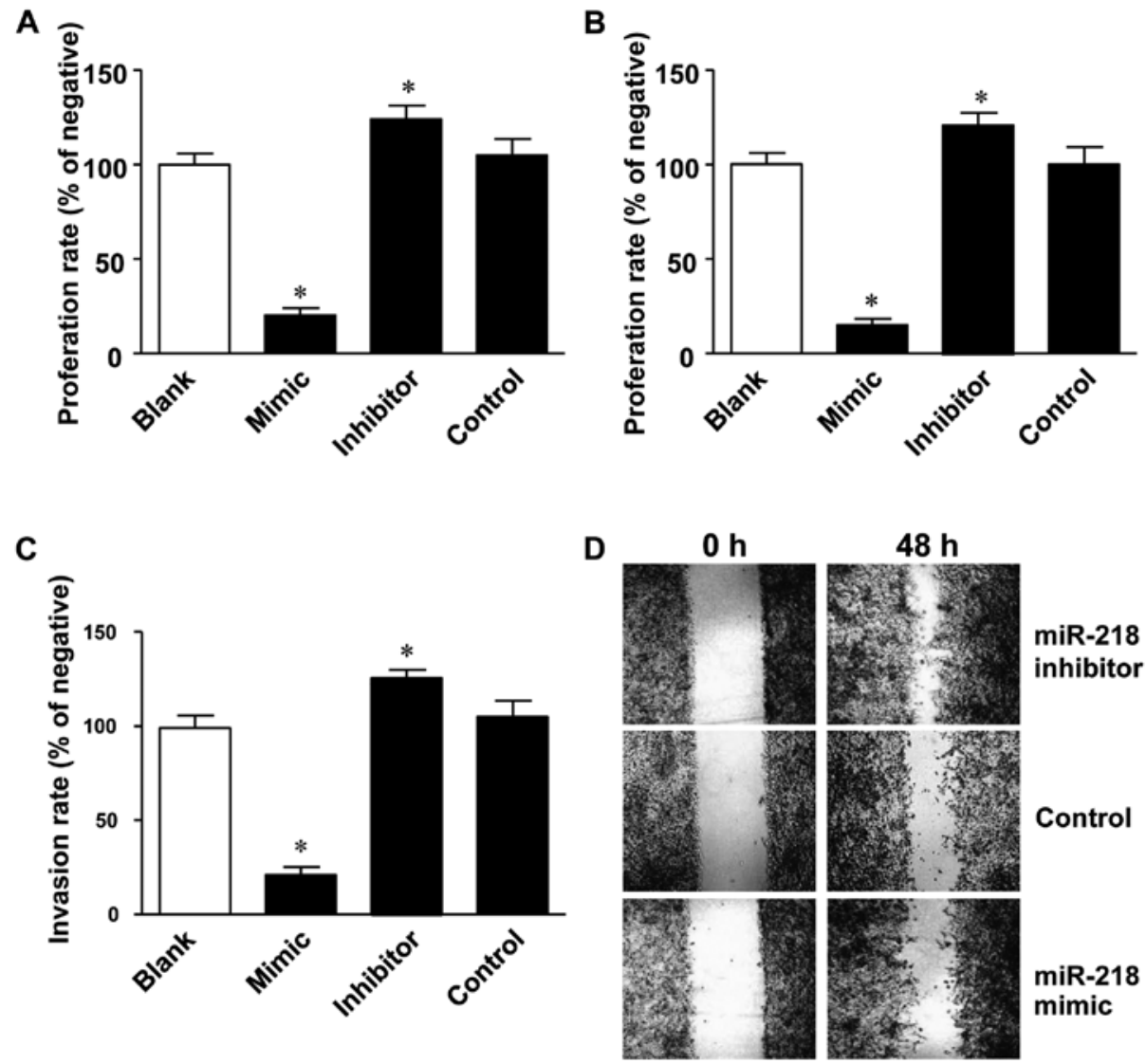

Figure 2. Cell proliferation, migration and invasion are regulated by miR-218. (A) MTT assay revealed that cell proliferation was significantly inhibited in the cells transfected with miR-218 mimics $(24.7 \pm 5.5 \%)$ as compared to the cells transfected with the non-specific control or miR-218 inhibitor. (B) Cell migration was significantly decreased in the cells transfected with miR-218 mimics $(19.7 \pm 5.0 \%)$, while miR-218 inhibitor promoted the migration of LoVo colon cancer cells $(117.0 \pm 9.6 \%)$. (C) Cell invasion was markedly inhibited in the cells transfected with miR-218 mimics $(28.3 \pm 7.6 \%$, while it was enhanced in the cells transfected with miR-218 inhibitor (118.7 $\pm 9.5 \%$ ), as shown by by Matrigel invasion assay. (D) Cells transfected with miR-218 mimics showed a slower wound closure rate than the cells transfected with the non-specific control or miR-218 inhibitor. ${ }^{*} \mathrm{P}<0.05$.

transfected group (117.0 $\pm 9.6 \%$ ) (Fig. 2B). Similar phenomena were also observed in the Matrigel invasion assay, in which the number of invading cells was reduced to $28.3 \pm 7.6 \%$ by transfection with miR-218 mimics and increased to $118.7 \pm 9.5 \%$ by transfection with miR-218 inhibitors (Fig. 2C). Furthermore, the rate of wound closure was slower in the miR-218 mimictransfected group, while the rate was increased in the miR-218 inhibitor-transfected group (Fig. 2D).

Regulation of the PI3K/Akt/mTOR signaling pathway by $m i R-218$. In order to investigate the molecular mechanisms underlying the miR-218-mediated development of colon cancer, the potential targets of miR-218 were predicted using the TargetScan database. Potential miR-218 target sites were detected in the 3' UTR of PIK3C2A (position 393-400 of PIK3C2A 3' UTR) and PIK3R1 (position 3591-3598 of PIK3R1 3' UTR) (Fig. 3A).

The effect of miR-218 on the PI3K/Akt/mTOR signaling pathway was further investigated in the LoVo colon cancer cells. It was shown that the expression levels of PI3K and mTOR at the mRNA and protein level were upregulated by transfection with miR-218 inhibitor, while they were markedly inhibited by transfection with miR-218 mimics (Fig. 3B, C and E). Furthermore, the phosphorylation of Akt was inhibited by transfection with miR-218 mimics, while it was promoted by transfection with miR-218 inhibitor (Fig. 3E). However, the expression of Akt at both the mRNA (Fig. 3D) and protein level (data not shown) was only slighlty altered following transfection with miR-218 mimics or inhibitor. These results indicate that $\mathrm{miR}-218$ is a negative regulator of the $\mathrm{PI} 3 \mathrm{~K} / \mathrm{Akt} / \mathrm{mTOR}$ signaling pathway.

Expression of MMP9 is inhibited by $\mathrm{miR}-218$. The degradation of basement membranes and the extracellular matrix is critical for tumor invasion and metastasis. MMPs, MMP2 and 9 in particular, are the most vital enzymes for extracellular matrix degradation in tumor invasion (33-35). This, in combination with the fact that miR-218 was found to negatively correlate with tumor migration and invasion, led us to investigate the effect of miR-218 on the expression of MMP9 and MMP2. As shown in Fig 4A, transfection with miR-218 mimics inhibited the expression of MMP9 at the mRNA level, while transfection with miR-218 inhibitor restored the mRNA expression of MMP9. However, MMP2 expression was only slightly altered in both the miR-218 mimic- and the miR-218 inhibitor-transfected cells (Fig. 4B).

Furthermore, the expression of MMP9 at the protein level was analyzed in the colon cancer tissue specimens. It was shown that MMP9 expression was significantly higher in the tumor tissues as compared to the adjacent normal tissues (Fig. 4C). 
A

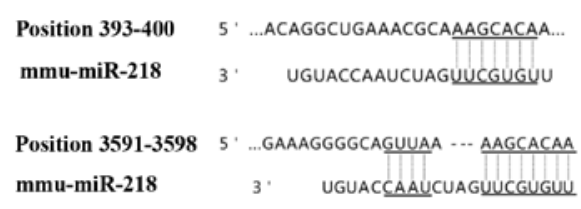

C

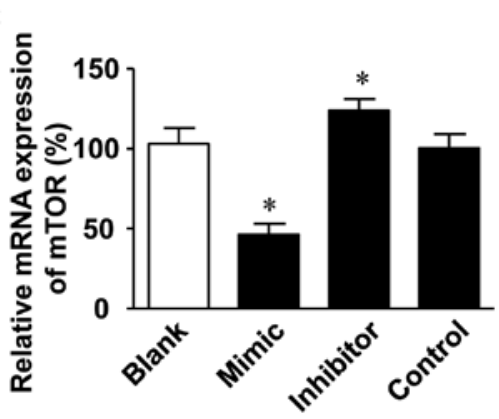

E

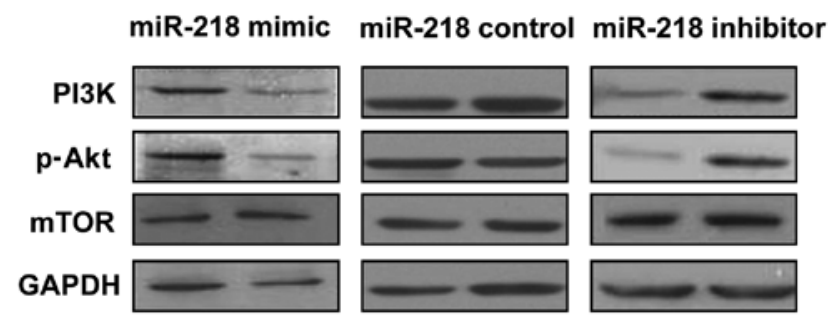

Figure 3. miR-218 regulates the phosphoinositide 3-kinase (PI3K)/protein kinase B (Akt)/mammalian target of rapamycin (mTOR) signaling pathway. (A) The TargetScan database revealed that miR-218 binds to the 3' UTR of PIK3C2A (position 393-400 of PIK3C2A 3' UTR) and PIK3R1 (position 3591-3598 of PIK3R1 3' UTR). (B) PI3K expression at the mRNA level was inhibited in the LoVo colon cancer cells transfected with miR-218 mimics, while it was promoted in the cells transfected with miR-218 inhibitor. (C) mTOR expression at the mRNA level was inhibited in the LoVo colon cancer cells transfected with miR-218 mimics, while it was promoted in the cells transfected with miR-218 inhibitor. (D) Akt expression at the mRNA level only slighlty altered following transfection with miR-218 mimics or inhibitor. (E) The expression of PI3K and mTOR at the protein level was examined by western blot analysis; miR-218 mimics inhibited their expression, while miR-218 inhibitor promoted it. The phosphorylation of Akt protein was inhibited by miR-218 mimics and was promoted by the miR-218 inhibitor in LoVo colon cancer cells. ${ }^{*} \mathrm{P}<0.05 ;{ }^{* *} \mathrm{P}<0.01$

However, MMP2 expression was quite similar between the colon cancer tissues and adjacent normal tissues (Fig. 4C). In addition to western blot anlaysis, immunofluorescence staining was employed to examine the effect of miR-218 on the expression status of MMP9 and MMP2 in the LoVo colon cancer cells, and the results revealed that transfection with the miR-218 inhibitor enhanced the expression of MMP9, while transfection with the miR-218 mimics inhibited MMP9 expression (Fig. 4D). However miR-218 had little effect on MMP2 expression (Fig. 4D).

\section{Discussion}

The survival and prognosis of colon cancer is poor, partly due to frequent tumor relapse and metastasis. Therefore, clarification of the molecular pathogenesis of colon cancer is crucial for developing effective therapeutic strategies to improve prognosis. In the present study, we focused on the correlation between miR-218 and the development of colon cancer. It was found that miR-218 expression was downregulated in the colon cancer cells and tissue samples. Furthermore, the inhibition of miR-218 in the human colon cancer cell line enhanced the cell migration and invasion ability, which was suppressed by the overexpression of miR-218. Indeed miR-218 has also been found to inhibit invasion and metastasis in other tumors, including gastric cancer $(36,37)$, head and neck squamous cell carcinoma (38) and cervical squamous cell carcinoma (39). These findings indicate that miR-218 is a potential tumor suppressor in colon cancer.

As described above, miR-218 functions as a tumor suppressor in several types of cancer, and multiple downstream targets, such as the Slit-Robol pathway (36), the Wnt signaling pathway (40) and the TGF $\beta$ signaling pathway (41), have been reported. In this study, we found that miR-218 binds to the 3' UTR of PIK3C2A (position 393-400) and PIK3R1 (position 3591-3598), indicating PI3K signaling as a potential 

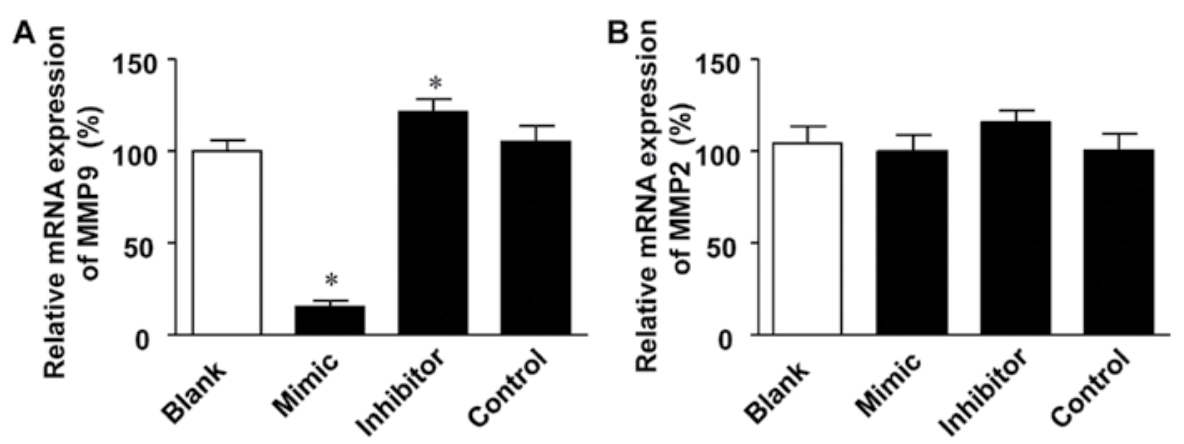

C
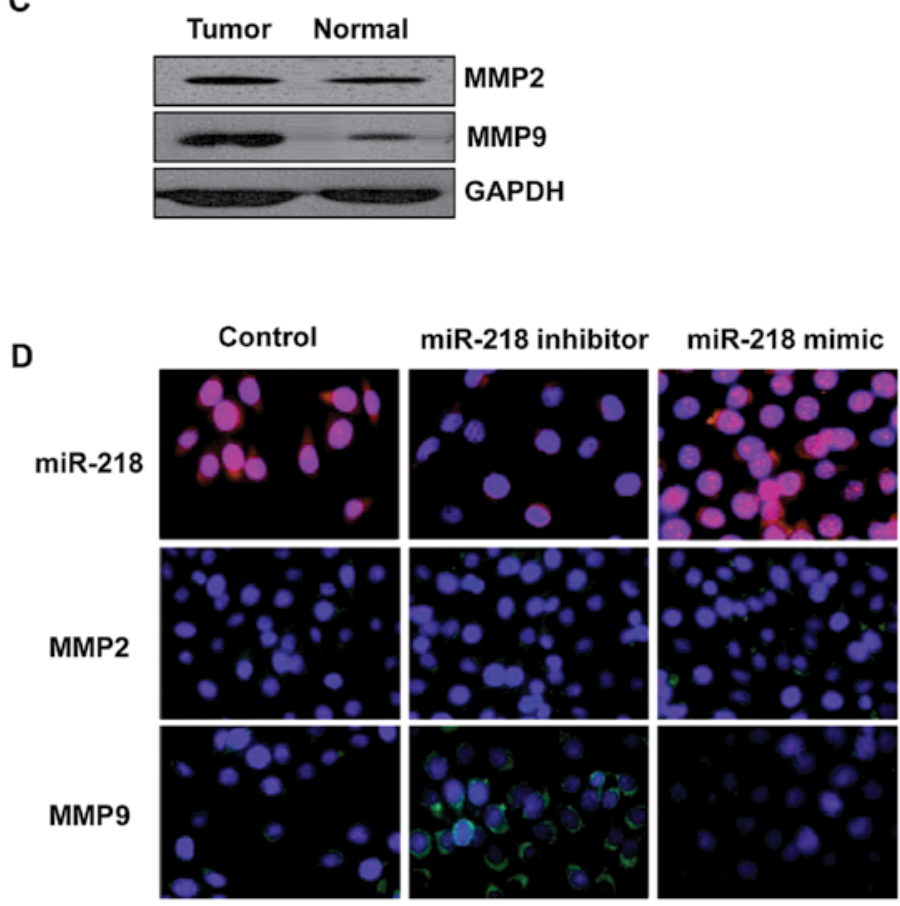

Figure 4. Effect of miR-218 on the expression of matrix metalloproteinase (MMP)9 and 2. (A) MMP9 expression at the mRNA level was inhibited by transfection with miR-218 mimics and was promoted by transfection with miR-218 inhibitor. (B) MMP2 expression at the mRNA level was not affected by transfection with miR-218 mimics or inhibitor in the LoVo colon cancer cells. (C) MMP9 expression at the protein level was significantly higher in the tumor tissues, whereas MMP2 expression was normal in the tumor tissues. (D) Immunofluorescence staining revealed that MMP9 expression was inhibited by transfection with miR-218 mimics and was promoted by transfection with miR-218 inhibitor. miR-218 mimics/inhibitor had little effect on MMP2 expression."P<0.05.

downstream pathway of miR-218. We further confirmed that miR-218 is an inhibitor of the PI3K/Akt/mTOR pathway in human colon cancer cells. PI3K is a membrane protein related to $\mathrm{G}$ protein-coupled receptors (42). PI3K activation triggers a series of intracellular events leading to the activation of $\mathrm{Akt}$ and mTOR (43-45), which thereafter induces the expression of multiple target genes that regulate cell proliferation, differentiation and other funtions $(46,47)$. Our results revealed that the PI3K/Akt/mTOR pathway was involved in the invasion and metastasis of colon cancer cells, which was negatively regulated by $\mathrm{miR}-218$.

The results of the present study demonstrated that cancer cell migration and invasion were inhibited by transfection with miR-218 mimics, whereas transfection with miR-218 inhibitor promoted the migration and invasion of colon cancer cells. These results indicate that miR-218 plays an important role in suppressing the metastasis of colon cancer cells. Furthermore, there was an inverse correlation between PI3K/Akt/mTOR expression and the miR-218 expression level in the colon cancer tissues, which was consistent with our in vitro results. These data confirmed that miR-218 inhibited colon cancer cell migration and invasion through the downregulation of PI3K/Akt/mTOR.

The activation of the PI3K signaling pathway is also associated with the hyper-expression of MMP, which accelerates tumor migration and invasion (48-51). Our results revealed that the activation of the PI3K/Akt/mTOR signaling pathway was enhanced and the expression levels of MMP9 were significantly higher in thecolon cancer tissues compared with the non-tumor tissues. Furthermore, the overexpression of miR-218 inhibited MMP9 expression and tumor aggressiveness. These results indicate that MMP9 is a downstream factor of miR-218 in regulating cancer cell invasion and migration.

In conclusion, our study demonstrated that miR-218 suppressed the invasion of colon cancer cells by inhibiting the activation of the PI3K/Akt/mTOR signaling pathway and MMP9 expression. Furthermore, the miR-218 expression level inversely correlated with both PI3K/Akt/mTOR and MMP9 
in the resected colon cancer tissues. These findings suggest that miR-218 is a potential target in the treatment of advanced colon cancer.

\section{Acknowledgements}

This study was supported by the Guangdong Province Natural Science Fund (no. S2013010016662), the Health Bureau of Guangdong Province (nos. A2014224 and B2014196), the Science and Technology Planning Project of Guangdong Province (no. 2013B021800284) and the National Natural Science Foundation of China (nos. 81201932 and 81372493).

\section{References}

1. Jemal A, Bray F, Center MM, Ferlay J, Ward E and Forman D Global cancer statistics. CA Cancer J Clin 61: 69-90, 2011.

2. Haggar FA and Boushey RP: Colorectal cancer epidemiology: Incidence, mortality, survival, and risk factors. Clin Colon Rectal Surg 22: 191-197, 2009.

3. Chen WQ, Zhang SW, Zou XN and Zhao P: Cancer incidence and mortality in China, 2006. Chin J Cancer Res 23: 3-9, 2011.

4. Simmonds PC, Primrose JN, Colquitt JL, Garden OJ, Poston GJ and Rees M: Surgical resection of hepatic metastases from colorectal cancer: A systematic review of published studies. $\mathrm{Br}$ J Cancer 94: 982-999, 2006.

5. Yokota M, Kojima M, Nomura S, Nishizawa Y, Kobayashi A, Ito M, Ochiai A and Saito N: Clinical impact of elastic laminal invasion in colon cancer: Elastic laminal invasion-positive stage II colon cancer is a high-risk equivalent to stage III. Dis Colon Rectum 57: 830-838, 2014.

6. Glehen O, Osinsky D, Cotte E, et al: Intraperitoneal chemohyperthermia using a closed abdominal procedure and cytoreductive surgery for the treatment of peritoneal carcinomatosis: Morbidity and mortality analysis of 216 consecutive procedures. Ann Surg Oncol 10: 863-869, 2003

7. Aghili M, Izadi S, Madani $\mathrm{H}$ and Mortazavi H: Clinical and pathological evaluation of patients with early and late recurrence of colorectal cancer. Asia Pac J Clin Oncol 6: 35-41, 2010.

8. Medina-Villaamil V, Martínez-Breijo S, Portela-Pereira P, Quindós-Varela M, Santamarina-Caínzos I, Antón-Aparicio LM and Gómez-Veiga F: Circulating MicroRNAs in blood of patients with prostate cancer. Actas Urol Esp 38: 633-639, 2014 (In English, Spanish).

9. Yang M, Liu R, Sheng J, Liao J, Wang Y, Pan E, Guo W, Pu Y and Yin L: Differential expression profiles of microRNAs as potential biomarkers for the early diagnosis of esophageal squamous cell carcinoma. Oncol Rep 29: 169-176, 2013.

10. Leite KR, Tomiyama A, Reis ST, Sousa-Canavez JM, Sañudo A, Camara-Lopes LH and Srougi M: MicroRNA expression profiles in the progression of prostate cancer - from high-grade prostate intraepithelial neoplasia to metastasis. Urol Oncol 31: 796-801, 2013.

11. He X, Dong Y, Wu CW, Zhao Z, Ng SS, Chan FK, Sung JJ and Yu J: MicroRNA-218 inhibits cell cycle progression and promotes apoptosis in colon cancer by downregulating BMI1 polycomb ring finger oncogene. Mol Med 18: 1491-1498, 2012.

12. Heckmann D, Maier P, Laufs S, et al: The disparate twins: A comparative study of CXCR4 and CXCR7 in SDF- $1 \alpha$-induced gene expression, invasion and chemosensitivity of colon cancer Clin Cancer Res 20: 604-616, 2014.

13. Yu H, Gao G, Jiang L, Guo L, Lin M, Jiao X, Jia W and Huang J: Decreased expression of miR-218 is associated with poor prognosis in patients with colorectal cancer. Int J Clin Exp Pathol 6: 2904-2911, 2013.

14. Fruman DA and Rommel C: PI3K and cancer: Lessons, challenges and opportunities. Nat Rev Drug Discov 13: 140-156, 2014.

15. Liu YZ, Wu K, Huang J, et al: The PTEN/PI3K/Akt and $\mathrm{Wnt} / \beta$-catenin signaling pathways are involved in the inhibitory effect of resveratrol on human colon cancer cell proliferation. Int J Oncol 45: 104-112, 2014.

16. Jiang QG, Li TY, Liu DN and Zhang HT: PI3K/Akt pathway involving into apoptosis and invasion in human colon cancer cells LoVo. Mol Biol Rep 41: 3359-3367, 2014.
17. Xiao ZM, Wang XY and Wang AM: Periostin induces chemoresistance in colon cancer cells through activation of the PI3K/Akt/survivin pathway. Biotechnol Appl Biochem: Dec 24, 2013 (Epub ahead of print).

18. Josse C, Bouznad N, Geurts P, Irrthum A, Huynh-Thu VA, Servais L,Hego A, Delvenne P, Bours V and Oury C: Identification of a microRNA landscape targeting the PI3K/Akt signaling pathway in inflammation-induced colorectal carcinogenesis. Am J Physiol Gastrointest Liver Physiol 306: G229-G243, 2014.

19. Dong M, Yang G, Liu H, Liu X, Lin S, Sun D and Wang Y: Aged black garlic extract inhibits HT29 colon cancer cell growth via the PI3K/Akt signaling pathway. Biomed Rep 2: 250-254, 2014.

20. Li XX, Huang LY, Peng JJ, Liang L, Shi DB, Zheng HT and Cai SJ: Klotho suppresses growth and invasion of colon cancer cells through inhibition of IGF1R-mediated PI3K/AKT pathway. Int J Oncol 45: 611-618, 2014.

21. Nuvoli B, Santoro R, Catalani S, Battistelli S, Benedetti S, Canestrari $\mathrm{F}$ and Galati R: CELLFOOD ${ }^{\mathrm{TM}}$ induces apoptosis in human mesothelioma and colorectal cancer cells by modulating p53, c-myc and pAkt signaling pathways. J Exp Clin Cancer Res 33: 24, 2014.

22. Enayat S, Ceyhan MS, Başaran AA, Gürsel M and Banerjee S: Anticarcinogenic effects of the ethanolic extract of Salix aegyptiaca in colon cancer cells: Involvement of Akt/PKB and MAPK pathways. Nutr Cancer 65: 1045-1058, 2013.

23. Trigka EA, Levidou G, Saetta AA, et al: A detailed immunohistochemical analysis of the PI3K/AKT/mTOR pathway in lung cancer: Correlation with PIK3CA, AKT1, K-RAS or PTEN mutational status and clinicopathological features. Oncol Rep 30: 623-636, 2013.

24. Banerjee N, Kim H, Talcott S and Mertens-Talcott S: Pomegranate polyphenolics suppressed azoxymethane-induced colorectal aberrant crypt foci and inflammation: Possible role of miR-126/VCAM-1 and miR-126/PI3K/AKT/mTOR. Carcinogenesis 34: 2814-2822, 2013.

25. Pandurangan AK: Potential targets for prevention of colorectal cancer: A focus on PI3K/Akt/mTOR and Wnt pathways. Asian Pac J Cancer Prev 14: 2201-2205, 2013.

26. Seo BR, Min KJ, Cho IJ, Kim SC and Kwon TK: Curcumin significantly enhances dual PI3K/Akt and mTOR inhibitor NVP-BEZ235-induced apoptosis in human renal carcinoma Caki cells through down-regulation of p53-dependent Bcl-2 expression and inhibition of Mcl-1 protein stability. PLoS One 9: e95588, 2014

27. Zang C, Eucker J, Liu H, Müller A, Possinger K and Scholz CW: Concurrent inhibition of PI3-kinase and mTOR induces cell death in diffuse large B cell lymphomas, a mechanism involving down regulation of Mcl-1. Cancer Lett 339: 288-297, 2013.

28. Kampa-Schittenhelm KM, Heinrich MC, Akmut F, Rasp KH, Illing B, Döhner H, Döhner K and Schittenhelm MM: Cell cycle-dependent activity of the novel dual PI3K-MTORC1/2 inhibitor NVP-BGT226 in acute leukemia. Mol Cancer 12: 46, 2013.

29. Müller A, Zang C, Chumduri C, Dörken B, Daniel PT and Scholz CW: Concurrent inhibition of PI3K and mTORC1/mTORC2 overcomes resistance to rapamycin induced apoptosis by down-regulation of Mcl-1 in mantle cell lymphoma. Int J Cancer 133: 1813-1824, 2013.

30. Malinowsky K, Nitsche U, Janssen KP, Bader FG, Späth C, Drecoll E, Keller G, Höfler H, Slotta-Huspenina J and Becker KF: Activation of the PI3K/AKT pathway correlates with prognosis in stage II colon cancer. Br J Cancer 110: 2081-2089, 2014.

31. Uesugi A, Kozaki K, Tsuruta T, Furuta M, Morita K, Imoto I, Omura $\mathrm{K}$ and Inazawa J: The tumor suppressive microRNA miR-218 targets the mTOR component Rictor and inhibits AKT phosphorylation in oral cancer. Cancer Res 71: 5765-5778, 2011.

32. Fan R, Zhong J, Zheng S, Wang Z, Xu Y, Li S, Zhou J and Yuan F: microRNA-218 increase the sensitivity of gastrointestinal stromal tumor to imatinib through PI3K/AKT pathway. Clin Exp Med: Apr 5, 2014 (Epub ahead of print).

33. Hadler-Olsen E, Winberg JO and Uhlin-Hansen L: Matrix metalloproteinases in cancer: Their value as diagnostic and prognostic markers and therapeutic targets. Tumour Biol 34: 2041-2051, 2013.

34. Stellas D and Patsavoudi E: Inhibiting matrix metalloproteinases, an old story with new potentials for cancer treatment. Anticancer Agents Med Chem 12: 707-717, 2012.

35. Shuman Moss LA, Jensen-Taubman S and Stetler-Stevenson WG: Matrix metalloproteinases: Changing roles in tumor progression and metastasis. Am J Pathol 181: 1895-1899, 2012. 
36. Tie J, Pan Y, Zhao L, et al: MiR-218 inhibits invasion and metastasis of gastric cancer by targeting the Robol receptor. PLoS Genet 6: e1000879, 2010.

37. Xin SY, Feng XS, Zhou LQ, Sun JJ, Gao XL and Yao GL: Reduced expression of circulating microRNA-218 in gastric cancer and correlation with tumor invasion and prognosis. World J Gastroenterol 20: 6906-6911, 2014.

38. Kinoshita T, Hanazawa T, Nohata N, et al: Tumor suppressive microRNA-218 inhibits cancer cell migration and invasion through targeting laminin-332 in head and neck squamous cell carcinoma. Oncotarget 3: 1386-1400, 2012.

39. Yamamoto N, Kinoshita T, Nohata N, Itesako T, Yoshino H, Enokida H, Nakagawa M, Shozu M and Seki N: Tumor suppressive microRNA-218 inhibits cancer cell migration and invasion by targeting focal adhesion pathways in cervical squamous cell carcinoma. Int J Oncol 42: 1523-1532, 2013.

40. Hassan MQ, Maeda Y, Taipaleenmaki H, et al: miR-218 directs a Wnt signaling circuit to promote differentiation of osteoblasts and osteomimicry of metastatic cancer cells. J Biol Chem 287: 42084-42092, 2012.

41. Guo F, Carter DE and Leask A: miR-218 regulates focal adhesion kinase-dependent TGF $\beta$ signaling in fibroblasts. Mol Biol Cell 25: 1151-1158, 2014.

42. Knight ZA, Gonzalez B, Feldman ME, et al: A pharmacological map of the PI3-K family defines a role for p110alpha in insulin signaling. Cell 125: 733-747, 2006.

43. Hales EC, Taub JW and Matherly LH: New insights into Notch1 regulation of the PI3K-AKT-mTOR1 signaling axis: Targeted therapy of $\gamma$-secretase inhibitor resistant T-cell acute lymphoblastic leukemia. Cell Signal 26: 149-161, 2014.

44. Serrano-Nascimento C, da Silva Teixeira S, Nicola JP, Nachbar RT, Masini-Repiso AM and Nunes MT: The acute inhibitory effect of iodide excess on sodium/iodide symporter expression and activity involves the PI3K/Akt signaling pathway. Endocrinology 155: 1145-1156, 2014.
45. Kim SM, Park JH, Kim KD, Nam D, Shim BS, Kim SH, Ahn KS, Choi SH and Ahn KS: Brassinin induces apoptosis in PC-3 human prostate cancer cells through the suppression of PI3K/Akt/mTOR/S6K1 signaling cascades. Phytother Res 28: 423-431, 2014.

46. Jung KH, Yan HH, Fang Z, Son MK, Lee H, Hong S and Hong SS: HS-104, a PI3K inhibitor, enhances the anticancer efficacy of gemcitabine in pancreatic cancer. Int J Oncol 45: 311-321, 2014.

47. Slotkin EK, Patwardhan PP, Vasudeva SD, de Stanchina E, Tap WD and Schwartz GK: MLN0128, an ATP-competitive mTOR kinase inhibitor with potent in vitro and in vivo antitumor activity, as potential therapy for bone and soft-tissue sarcoma. Mol Cancer Ther 14: 395-406, 2015

48. Yuan H, Yang P, Zhou D, Gao W, Qiu Z, Fang F, Ding S and Xiao W: Knockdown of sphingosine kinase 1 inhibits the migration and invasion of human rheumatoid arthritis fibroblast-like synoviocytes by down-regulating the PI3K/AKT activation and MMP-2/9 production in vitro. Mol Biol Rep 41: 5157-5165, 2014

49. Yang N, Hui L, Wang Y, Yang H and Jiang X: SOX2 promotes the migration and invasion of laryngeal cancer cells by induction of MMP-2 via the PI3K/Akt/mTOR pathway. Oncol Rep 31: 2651-2659, 2014

50. Su Y, Gao L, Teng L, Wang Y, Cui J, Peng S and Fu S: Id1 enhances human ovarian cancer endothelial progenitor cell angiogenesis via PI3K/Akt and NF-кB/MMP-2 signaling pathways. J Transl Med 11: 132, 2013.

51. Li X, Yang Z, Song W, et al: Overexpression of Bmi-1 contributes to the invasion and metastasis of hepatocellular carcinoma by increasing the expression of matrix metalloproteinase (MMP)-2, MMP-9 and vascular endothelial growth factor via the PTEN/PI3K/Akt pathway. Int J Oncol 43: 793-802, 2013. 